\author{
J. Phys. IV France 12 (2002), pp. 57-52 \\ (C) EDP Sciences, Les Ulis \\ DOI: 10.1051/jp4:20020452
}

\title{
Climate-vegetation interaction
}

\author{
V. Brovkin
}

Potsdam Institute for Climate Impact Research, P.O.Box 601203, 14412 Potsdam, Germany

\begin{abstract}
The climate exerts the dominant control on the spatial distribution of the major vegetation types on a global scale. In turn, vegetation cover affects climate via alteration of the physical characteristics of the land surface like albedo, roughness, water conductivity (biogeophysical mechanisms) and atmospheric gas composition, for example, $\mathrm{CO}_{2}$ and $\mathrm{CH}_{4}$ (biogeochemical effects). The chapter covers biogeophysical interactions between the land surface and the atmosphere. Recent progress in vegetation and land surface modelling is briefly discussed. Research on climate-vegetation interaction is mostly concentrated on "hot spots" where the interaction is the most significant: boreal forests, North Africa, and Amazon forest. Boreal forests, even deciduous ones, significantly reduce the albedo of snow-covered surfaces. Simulations with different climate models reveal that positive feedback between forest and surface air temperature in the boreal region is not strong enough to establish multiple steady states. Nonetheless, the simulations show a significant cooling trend due to historical land cover changes, mainly as a result of temperate and boreal deforestation. In general, the climate models agree that tropical deforestation exerts a net regional warming while an effect on extratropical regions is more uncertain. In the Sahel/Sahara region, several models are able to simulate ,green Sahara“ phenomenon during the mid-Holocene. Some models reveal multiple steady states in the region due to a strong interaction between vegetation and monsoon precipitation. Sensitivity simulations show that some expansion of vegetation cover into the Sahara is possible under $\mathrm{CO}_{2}$-induced climate changes.
\end{abstract}

\section{INTRODUCTION}

A visual comparison of climate and vegetation on a global scale immediately reveals a strong correlation between climatic and vegetation zones: the moist tropics are associated with tropical forest, the dry subtropics with subtropical deserts, regions of temperate climate with temperate/boreal forests, and polar regions with tundra/polar desert. These relationships, of course, are not co-incidental. The central thesis for plant ecology is that climate exerts the dominant control on the spatial distribution of the major vegetation types on a global scale, while on a smaller scale, the contribution of secondary factors such as soil type or topography are important as well $[1,2]$. Climate, in the given context defined as a seasonal course of solar radiation, temperature, and precipitation, primarily determines the predominant type of terrestrial vegetation (e.g., broadleaved forest, grassland) and the biogeochemical properties of the land surface (e.g., $\mathrm{CO}_{2}$ flux, carbon storage in biomass and soil). In turn, vegetation cover affects climate via alteration of the physical characteristics of the land surface like albedo, roughness, water conductivity (biogeophysical mechanisms) and atmospheric gas composition, for example, $\mathrm{CO}_{2}$ and $\mathrm{CH}_{4}$ (biogeochemical effects). The chapter covers only biogeophysical interactions between the land surface and the atmosphere (Fig. 1), as discussion of biogeochemical interactions ultimately involves oceanic biogeochemistry.

Here, biogeophysical interactions are substantially simplified in order to provide a short overview of the current state of research. Among these simplifications, the most important are: (i) a reduction of ecosystems to plants only, as the biomass storage in plants exceeds the biomass of animals and other living organisms by an order of magnitude; (ii) a reduction of the vast diversity of plants to a few major plant types representative for vegetation cover; (iii) neglecting the non-climatic factors which control vegetation on a local scale, e.g. soil type or topography. Some of the neglected ecosystem components are implicitly accounted for, like the function of microorganisms in mineralising dead organic matter. Among 
the other simplifications, the interaction mechanisms are limited to first-order effects, such as through albedo and transpiration, which are the focus of the current research.

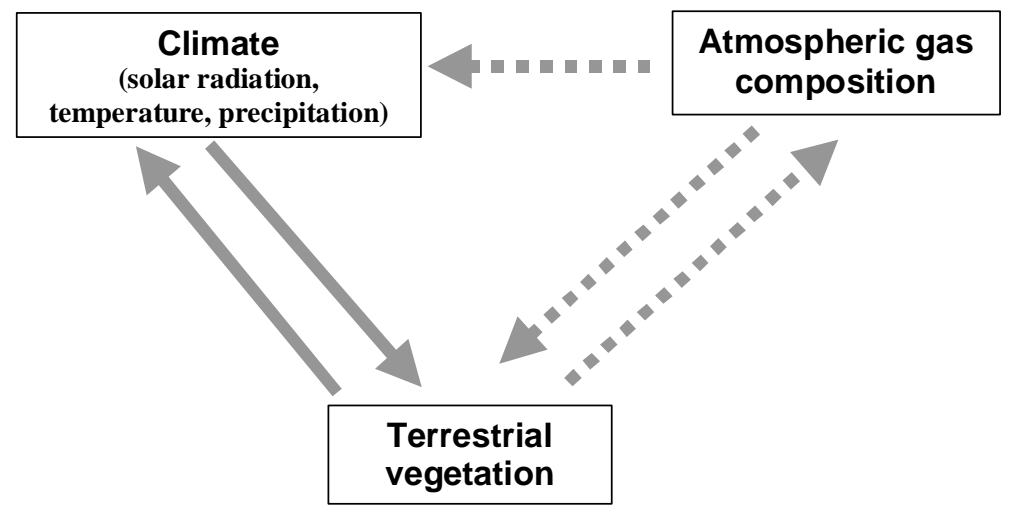

Figure 1. Interaction between climate and vegetation. Only biogeophysical interactions (solid lines) are discussed in the chapter.

\subsection{Climatic control of vegetation cover}

Agricultural development during the last several thousand years led to widespread testing of plant adaptation abilities outside the areas of their natural habitat. This process, as well as extensive geographical exploration, revealed the existence of a remarkable correlation between vegetation and climate. Alexander von Humbolt [3] was among first geographers to analyse climate-vegetation relationships on a global scale and investigate links between climate and vegetation changes in the past. Since then, regularities in climate and plant distribution have been systematically explored within such scientific disciplines as biogeography, plant ecology, and recently, macroecology [4-7].

Although vegetation-climate relationships are remarkable, the mechanisms behind these interconnections are not completely understood. While progress in plant physiology and biochemistry has clarified most of the biochemical mechanisms on a leaf or plant scale, like photosynthesis and plant growth, processes on the ecosystem level, such as plant competition and plant succession (replacement of one plant species by another) are much more poorly explored. One of the obvious obstacles is the long time scale for vegetation re-growth, which is up to hundred years for forest ecosystems. Because alteration of the soil organic profile in response to changes in vegetation cover is even slower, the evolution of ecosystems towards equilibrium with the environment takes up to several thousand years. In contrast, systematic observations of changes in vegetation cover and soil profile are available up to several hundred years at most. For significant parts of the globe, these data are limited to the last several decades. Another difficulty is that in the most explored regions, like Europe, the natural vegetation cover has been replaced for centuries by croplands and planted forests.

Due to limitations in available time-series, a conventional approach in biogeographic analysis is the substitution of time by space via the analysis of geographical climate-vegetation regularities, under the assumption that observed natural ecosystems are in equilibrium with climate. A basic outcome of this method is that trees (woody species) have preference over grass (herbaceous plants) in the case of significant available resources (radiation, water, nutrients), as a result particularly of the better interception of light by dense tree canopies. With increase in water stress across a wet-dry gradient, shrub/grass ecosystems become more prevalent than trees due to various factors including different root depth and fire vulnerability. In extremely dry regions, there is virtually no vegetation. Similar regularity exists across a warm-cold gradient [2]. With a drop in temperature below a certain threshold, tall trees cannot be sustained while low plants (shrubs, forbs, grass, moss) can survive extremely cold winter temperatures under snow cover. In extremely cold polar and alpine deserts there is a sparse presence of moss and lichens. 


\subsection{Vegetation models}

Köppen's climate classification system [8] was among the firsts attempts to establish quantitative relationships between climate and vegetation on a global scale. Holdridge [9] used three climatic variables (predictors) - annual precipitation, bio-temperature (temperature above $0^{\circ} \mathrm{C}$ ), and ratio of mean annual potential evapotranspiration to mean total annual precipitation - to separate 38 climatic "life zones" from each other. In the BIOME model, Prentice et al. [10] classified 13 plant functional types (PFT) in accordance with 5 climatic predictors: the sum of degree-days (the sum of temperatures above $0^{\circ} \mathrm{C}$ or $5^{\circ} \mathrm{C}$ ), mean temperatures of the coldest and the warmest months, and the ratio of annual actual evapotranspiration to annual potential evapotranspiration. The simplicity of the BIOME model and the powerful ecophysiological basis of its predictors led to widespread use of the model in simulations of the equilibrium response of vegetation to climatic changes.

In the recent generation of global vegetation models, trees are classified in accordance with their leaf form (e.g., broadleaved, needleleaved) and phenology (evergreen, deciduous, raingreen) as well as climatic preferences (tropic, temperate, boreal). Despite a vast diversity of herbaceous plants, the number of grass types is reduced to just a few in accordance with their climatic occurrence (tropic, temperate, tundra) and type of photosynthesis: $\mathrm{C}_{3}$-type and $\mathrm{C}_{4}$-type. In accordance with the PFT approach, intermediate vegetation classes like woodland and shrubs are often presented as mixtures of trees and grasses. In some models, crops are included in order to have more realistic representation of present-day vegetation cover. Recent progress in remote sensing techniques allows the generation of global maps of the actual distribution of PFTs from satellite data [11].

Independently of the biogeographical models, vegetation models that simulate terrestrial biogeochemistry (carbon cycle) based on a given distribution of vegetation have been developed and applied, for example, for analysis of changes in terrestrial carbon storage under various scenarios of global climate change [12-15]. Most of the process-based biogeochemical models simulate photosynthesis, growth and maintenance respiration, phenology (seasonal leaf development), allocation of assimilated carbon into different plant tissues (stem, roots), as well as accumulation and mineralisation of dead organic matter in soils. In addition, the models simulate stomatal conductance which regulates the exchange of $\mathrm{CO}_{2}$ and water vapour between the plants and the atmosphere. The soil water budget is also calculated in order to account for water stress effects on plant productivity. A recent overview of biogeochemical models can be found in [16-17].

During the last decade, another generation of vegetation models, so-called dynamic global vegetation models (DGVMs), has emerged [18-19]. In addition to simulation of the biogeographical limits of different PFTs and terrestrial biogeochemistry, these models account for long-term processes of changes in vegetation cover in response to environmental changes. Some of these models simulate changes in PFT fractional cover based on explicit sets of dynamic equations like Lotka-Volterra or evolutionary equations [20-21]. Other models simulate the competition among PFTs explicitly based on the assumption that PFTs with higher productivity have preference in competition. The latter model class simulates disturbances of vegetation growth, like fire frequency, and accounts for the effect of disturbances on the dynamics of carbon storage and vegetation succession.

\subsection{Land surface parameterisations in climate models}

Vegetation modifies energy, water, momentum, and $\mathrm{CO}_{2}$ fluxes at the land surface. The net balance of the radiation absorbed by the land surface, $R_{n}$, is determined as

$$
R_{n}=S(1-\alpha)+L_{w}-\varepsilon \sigma T_{S}^{4},
$$

where $S$ is insolation, $\alpha$ is the surface albedo, $L_{w}$ is downward long-wave flux, $\varepsilon$ is the surface emissivity, $\sigma$ is the Stefan-Boltzmann constant and $T$ is the land surface temperature [22-23]. $R_{n}$ is portioned into three heat flux terms 


$$
R_{n}=H+\lambda E+G
$$

where $G$ is the ground heat flux, $H$ is the sensible heat flux, $E$ is the evapotranspiration rate, and $\lambda$ is the latent heat of vaporisation (Fig. 2).
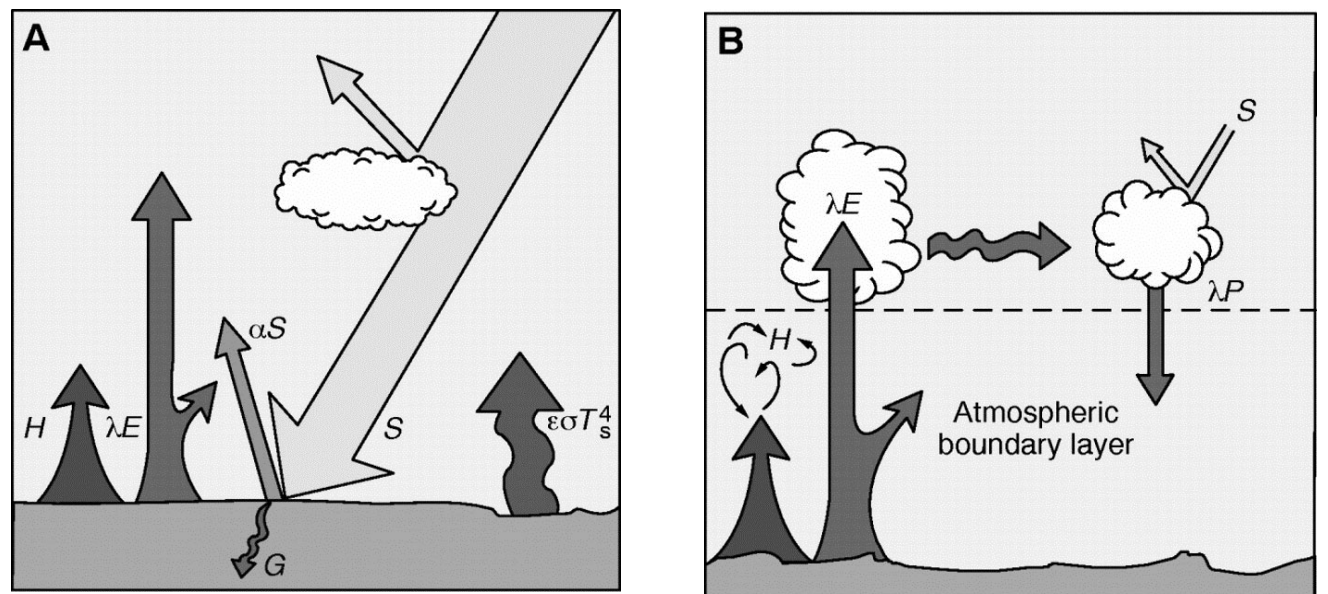

Figure 2. Interactions between the land surface and the atmosphere that have direct impacts on the physical climate system. (A) Surface radiation budget. (B) Effect of heat fluxes on the atmosphere. Reprinted with permission from Sellers et al. [23]. Copyright 1997 American Association for the Advancement of Science.

On a global average, of 100 units of energy entering the global climate system, 46 are absorbed by the surface and 31 are exchanged in the form of sensible and latent heat [24]. Vegetation influences the absorption of energy by the surface via modification of the surface albedo as well as via alteration of energy partitioning between sensible and latent heat. Additionally, vegetation modifies the surface roughness length. These processes are accounted for by soil-vegetation-atmosphere transfer schemes (SVAT) which serve as land surface modules within atmospheric general circulation models (GCMs). In their review of land surface parameterisations, Sellers et al. [23] explored the historical development of three generations of SVAT schemes. The third-generation schemes are able to solve coupled systems of equations for leaf photosynthesis and stomatal conductance. The latter controls plant transpiration and, therefore, latent heat flux. Some of the SVAT schemes account for sub-grid-scale parameterisation of hydrological processes within the model grid cell in order to simulate wetland distribution. In a recent review of SVAT schemes, Arora [17] overviews the biogeochemical processes within process-based vegetation models and illustrates the manner in which the coupling of vegetation models and SVAT schemes may be accomplished.

\section{HOT SPOTS OF CLIMATE-VEGETATION INTERACTION}

Regional climate depends on both local and remote factors. In regions with strong zonal atmospheric circulation, like the northern middle latitudes, the effect of local vegetation changes on the regional climate may be smaller than the effects due to such changes in remote regions. At the same time, changes in vegetation cover affect not only the region with altered vegetation, but also neighbouring regions. The local effect is most pronounced for temperature, as vegetation changes directly affect the local radiative budget. Changes in vegetation also alter the evaporation. However, changes in air moisture content may result in quite remote effects due to the long-distance transport of moisture. For example, in Europe there is a general reduction in precipitation towards the continent's interior as the transport of moisture from the Atlantic Ocean declines with distance to the ocean. A substantial fraction of precipitation re-evaporates via plant transpiration. The significance of water recycling on a way of moisture transport increases for continental regions. Thus, changes in regional climate depend on both remote and local changes in vegetation. 
The effect of vegetation on regional climate is not the same around the globe. Research on climatevegetation interaction is mostly concentrated on several "hot spots" where the interaction is the most pronounced. Among these regions, the most significant are mid- and high latitude forests in the northern hemisphere (boreal forests), subtropical deserts and semideserts in North Africa (Sahara/Sahel region), and tropical rainforest in South America (Amazon forest).

\subsection{Boreal forests and climate}

Forests affect climate in a multitude of ways. Changes in the water and radiative budgets are the most significant factors. Although summer water stress is possible in the continental interior of the northern high latitudes, the key limiting factor for tree growth in the region is the heat (or temperature) factor, which can be expressed in terms of the sum of degree-days. At the same time, the physical characteristics of trees (e.g., height, albedo, roughness, stomatal conductance) differ from those of grass or moss or bare ground. Such differences, in turn, explain the effect of land cover change on climate.

Forests, even deciduous ones, significantly reduce the albedo of snow-covered surfaces [25]. This is the basis for the radiative feedback between forest and surface air temperature: increased tree fraction $\rightarrow$ decreased surface albedo during snow season $\rightarrow$ increased air temperature and earlier snow melt $\rightarrow$ longer and warmer growing season $\rightarrow$ increased tree fraction. This feedback is positive, i.e. it amplifies the system response to the original external forcing (Fig. 3). This feedback is dampened during the growing season, when trees have a denser, more productive canopy than herbaceous plants and moss, and, therefore, transpire more water. This suggests a greater latent heat flux and a cooling of surface air in forests as compared to tundra [26-27]. This hydrological feedback, although negative (see Fig. 3), is secondary to the radiative feedback on the annual average.

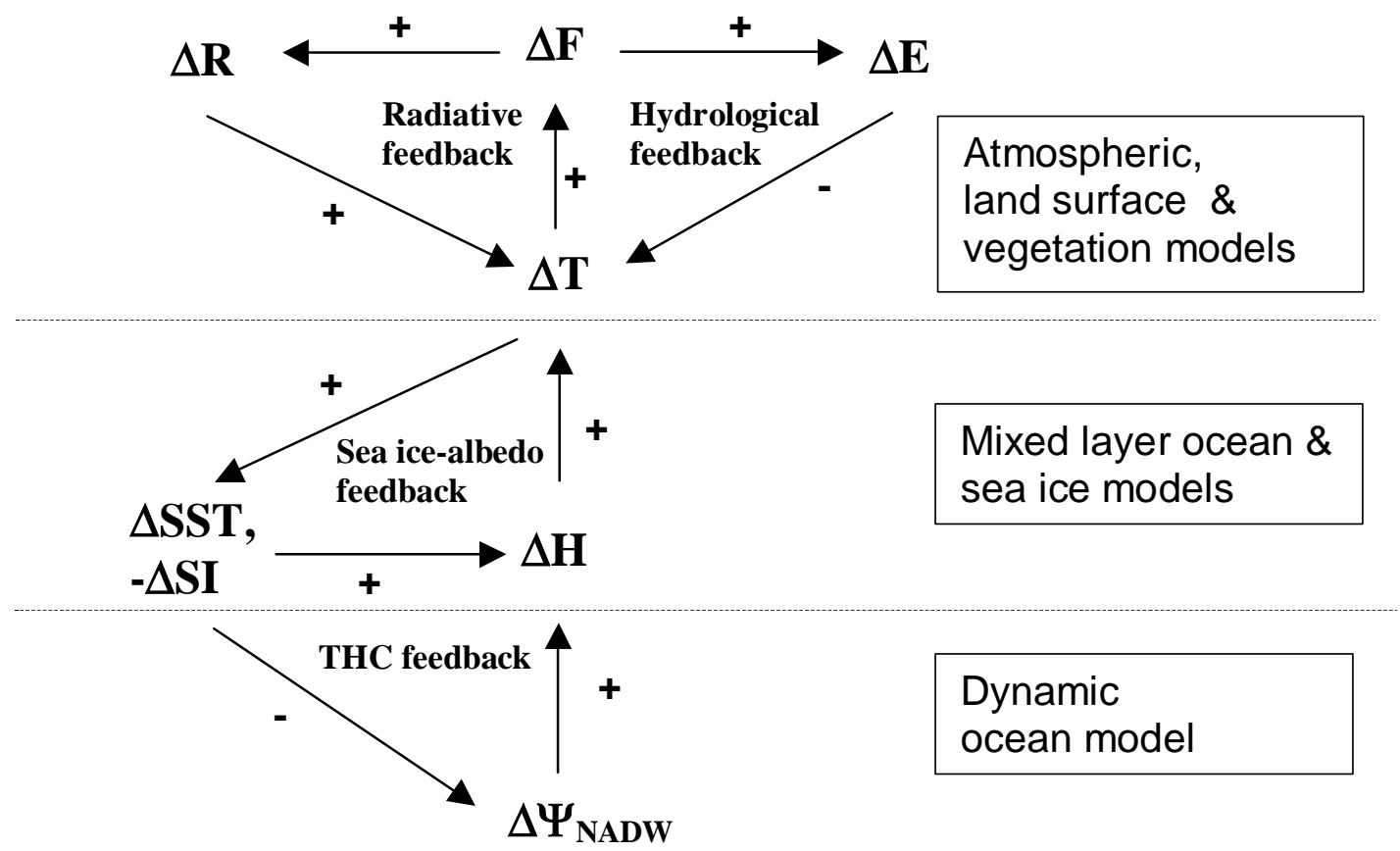

Figure 3. Sketch of climate-vegetation interactions in the northern high latitudes and hierarchy of model compartments in the feedback analysis. The arrows on the left indicate relations between variables, including amplification (+) or dampening (-) of the original change $\Delta$. F refers to the tree fraction; $\mathbf{T}$, to surface air temperature; $\mathbf{R}$, to the net radiation at the surface; $\mathbf{E}$, to evapotranspiration; SST, to sea surface temperature; SI, to sea ice; $\mathbf{H}$, to heat fluxes out of the ocean and into the atmosphere; $\Psi_{\text {NADW }}$, to the intensity of the thermohaline circulation. The boxes in the middle indicate model compartments necessary to investigate feedbacks shown on the left. After Brovkin et al. [28]. 
The radiative feedback was first explored in simulations with multilayer energy balance models [2930]. These studies found significant hemispheric cooling in the absence of boreal forests masking the snow. After land surface schemes in GCMs began to consider different vegetation types explicitly, the impact of boreal vegetation on climate became a model benchmark. Sensitivity simulations with GCMs done by Bonan et al. [31], Thomas and Rowntree [32], Chalita and Le Treut [33] confirmed the cooling effect of boreal deforestation. Their analysis was primarily focused on radiative effects. The subsequent studies [34-37] revealed that during the summer the hydrological effect of deforestation is comparable to the radiative effect. Paleosimulations for the mid-Holocene [38-43], the last glacial maximum [44-45], and the last interglacial [46-49] highlighted the boreal forest-climate feedback as an amplifier of externally driven climate change.

Most of GCM simulations were done with sea surface temperatures (SSTs) and sea ice prescribed from present-day observations. However, the radiative and hydrological feedbacks depend on the oceanic response. Particularly, the original increase in forest area can be amplified by the sea ice - albedo feedback: increased surface air temperature $\rightarrow$ increased SSTs and decreased sea ice area $\rightarrow$ decreased surface albedo $\rightarrow$ increased surface air temperature (see Fig. 3). The significance of the sea ice - albedo feedback was first shown in boreal deforestation simulations done by Harvey [30] and Bonan et al. [31]. They used mixed layer ocean models and thermodynamic sea-ice models which are computationally inexpensive. However, SST and sea-ice changes, especially in the region of Atlantic deep water formation, are dampened by a negative feedback due to the thermohaline circulation (THC): increased SSTs $\rightarrow$ lower density of the surface water $\rightarrow$ decreased thermohaline overturning and northward oceanic heat transport $\rightarrow$ reduced SSTs. This and other feedbacks associated with changes in the oceanic circulation (see, e.g., [50]) can be generated only by dynamic ocean models which simulate ocean circulation. The time scale of deep ocean dynamics is several hundred years, so the long-term effect of boreal deforestation on the THC has not been explored with coupled atmosphere-ocean GCMs.

One of the most important aspects of interaction analysis is whether the interaction is strong enough to establish a second equilibrium. To investigate the stability of a system, it is useful to reduce the system's complexity to the minimum: one variable for climate (temperature) and one for vegetation (tree fraction) $[28,51]$. The surface air temperature $\boldsymbol{T}$ is expressed in terms of growing degree-days above 0 degrees Celsius $\left(\mathrm{GDD}_{0}\right)$. The tree fraction $\boldsymbol{F}$ is the fraction of land covered by a tree canopy; during the snow season, trees are assumed to be taller than snow depth. The remaining land fraction is covered by non-tree vegetation (e.g. grass, moss) or no vegetation (bare ground). When vegetation and climate are in equilibrium, the values of $\boldsymbol{F}$ and $\boldsymbol{T}$ solve the following system of equations:

$$
\left\{\begin{array}{l}
F=F *(T, E) \\
T=T *(F, E)
\end{array}\right.
$$

where $\boldsymbol{F}^{*}(\boldsymbol{T}, \boldsymbol{E})$ is an equilibrium dependence of vegetation on climate, or, in mathematical terms, an equilibrium manifold for the variable $\boldsymbol{F}$. This manifold is obtained from the vegetation model assuming that $\boldsymbol{T}$ varies independently and not in response to tree fraction changes. Similarly, $\boldsymbol{T} *(\boldsymbol{F}, \boldsymbol{E})$ is an equilibrium dependence of the climate on vegetation which is obtained from the atmosphere/ocean model assuming that $\boldsymbol{F}$ varies independently and not in response to temperature changes. The climate system components outside the area of consideration (e.g. SST, sea ice) are assumed to be in equilibrium with $\boldsymbol{F}$ and $\boldsymbol{E}$. The points of intersection of the curves $\boldsymbol{F}^{*}(\boldsymbol{T}, \boldsymbol{E})$ and $\boldsymbol{T}^{*}(\boldsymbol{F}, \boldsymbol{E})$ in Fig. 4 represent solutions of the system (3) or equilibria of the climate-vegetation system. The most interesting question is whether this is unique or multiple. 


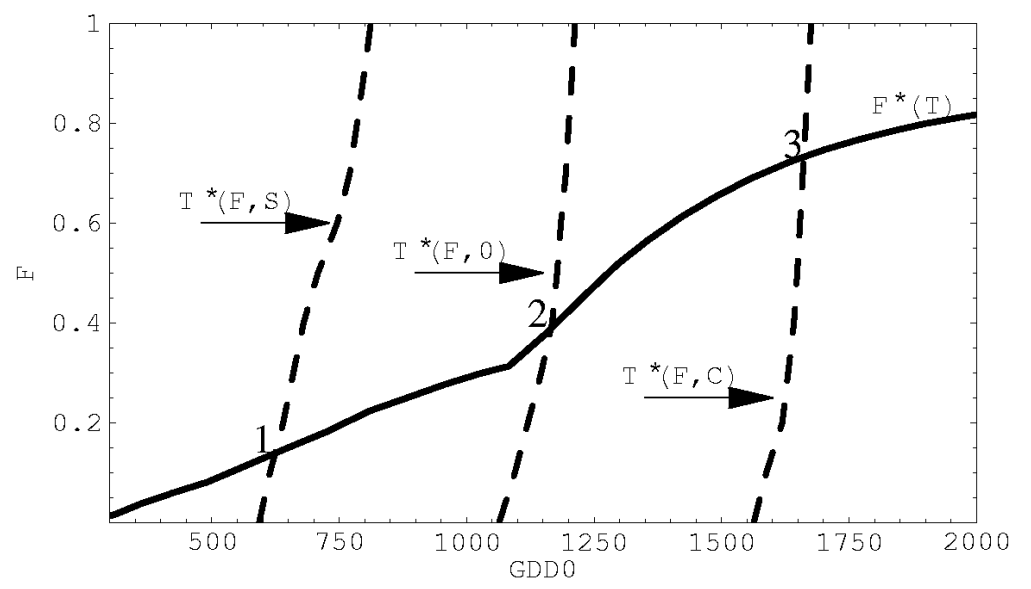

Figure 4. Interpretation of CLIMBER-2 results in terms of a conceptual model (after Brovkin et al. [28]). The solid curve represents $\boldsymbol{F}^{*}(\boldsymbol{T})$, the dashed lines are for $\boldsymbol{T}^{*}(\boldsymbol{F}, \boldsymbol{E})$. Points 1,2 , and 3 are steady states in present-day $(0)$, doubled $\mathrm{CO}_{2}(\mathrm{C})$, and decreased insolation $(\mathrm{S})$ simulations, respectively.

To check this hypothesis, several models have been applied [28]: a three-dimensional model (GENESIS-IBIS [45, 51]) and two Earth System models of intermediate complexity, or EMICs (CLIMBER-2 [52, 53] and MoBidiC [43, 49]). Results of numerical experiments are interpreted in terms of equilibrium manifolds on a phase plane (Fig. 4). A unique steady state is simulated by all the models on a zonal scale for present-day climate and doubled $\mathrm{CO}_{2}$ climate. Decreased insolation experiments with the EMICs also result in a unique equilibrium. In sensitivity experiments with CLIMBER-2, no multiple steady states on a zonal scale are found for intentionally changed parameterizations of snow and forest albedos. However, we cannot rule out the possibility of multiple steady states, for example, due to local scale interactions.

The EMIC simulations show lower climate sensitivity (expressed in degree-days) with higher tree fractions. This is mainly due to an increase in both air temperature and the length of the snow-free season with increasing tree fractions. The radiative effect of forests on air temperature is higher in spring than in summer. However, the relative effect of spring temperatures in accumulated degree-days decreases, the longer the snow-free season. Therefore, the feedback between forest and temperature is weaker for higher tree fractions and stronger for lower tree fractions.

The GENESIS-IBIS and CLIMBER-2 simulations reveal that the climate sensitivity to changing tree fraction is higher for the present-day than for the warmer doubled $\mathrm{CO}_{2}$ climate. In particular, the warmer climate has a shorter snow season, which leads to a decrease in the significance of the radiative feedback. Simultaneously, as the growing season lengthens, the hydrological feedback increases in importance.

Experiments with the EMICs explored the effect of changes in ocean circulation on the climate sensitivity to forest cover in the boreal region. These simulations indicate that the sensitivity is smaller with fixed SSTs and sea ice than with an interactive ocean (CLIMBER-2), which is in turn smaller than with a mixed layer ocean. The mixed layer ocean and interactive sea ice amplify the radiative and hydrological feedbacks which originate on land, while feedbacks associated with THC changes dampen the signal.

There is growing observational evidence of recent changes in the northern high-latitude environment including a decline in Arctic sea ice cover, a rise in surface air temperature and photosynthetic activity of plants, and even indicators of a northward trend in the position of the tree line [54-55]. EMIC simulations driven with a scenario of transient $\mathrm{CO}_{2}$ reveal that in the 1990s the rate of tree fraction $\boldsymbol{F}$ increase in this region was about $1 \%$ per decade, while the equilibrium tree fraction $\boldsymbol{F}^{*}$ grows at a rate of about $1 \%$ per decade. This points to the significant disequilibrium between present-day climate and vegetation cover in the northern high latitudes, due to a delay in the vegetation's response. Under accelerated $\mathrm{CO}_{2}$ warming, the rate of change in vegetation cover in the following two decades doubles in the models to $2 \%$ per decade. The changes in vegetation cover, in turn, amplify regional warming, although the feedback weakens as the climate warms. 
Fig. 4 is a simplified cartoon of the complex climate-vegetation interaction in the northern high latitudes. Keeping in mind model's limitations, it is important to investigate feedbacks with a spectrum of models of different complexity. All classes of models, from greatly simplified conceptual models to highresolution regional GCMs, play an important role in this analysis.

\subsection{Tropical deforestation}

Tropical forests in South-America, Africa and Southeast-Asia are being deforested to make land available for agriculture. The main impacts of deforestation on surface conditions are increase in surface albedo, reduced net evaporation as well as decrease in surface roughness. In general, the climate models agree that tropical deforestation exerts a net regional warming [53, 56-58] while an effect on extratropical regions is more uncertain [59]. Increase in surface albedo is partly compensated by decrease in cloud cover. Theoretically, tropical deforestation should result in decrease in moisture convergence and precipitation because of reduction of evapotranspiration. The latter is found in most of climate model simulations as well as in the ground observations like in Large Scale Biosphere-Atmosphere Experiment in Amazonia [60]. However, several mechanisms prevent reduction of moisture convergence. For example, the lower roughness of pasture favors the converging low level fluxes in the region. Heterogeneity of landscape and deforestation patterns affects fluxes in a multitude of ways which are difficult to account for within coarse-resolution global climate models [61].

Partial deforestation of Amazon region reveals to be a natural phenomenon in transient simulations of Hadley Centre climate model under scenario of increasing $\mathrm{CO}_{2}$ emissions [62]. Within the model, dieback of Amazon forest is a consequence of a decrease in rainfall due to large-scale changes in atmospheric circulation induced by the global warming. A replacement of trees with shrubs and grass, as well as an increase in stomatal conductance due to elevated atmospheric $\mathrm{CO}_{2}$ concentration, result in a lower transpiration which, in turn, amplifies decrease in precipitation. Reduction in the forest biomass in the region leads to higher $\mathrm{CO}_{2}$ emissions, which additionally amplifies the global warming. However, global climate models are not consistent in the predicted patterns of rainfall changes in tropics under scenario of elevated greenhouse gases [63]. Possibility of the dieback of Amazon forest and the acceleration of the global warming is being investigated in more details (see, e.g., [64]).

\subsection{Historical land-cover changes}

During the last millennium, mankind has significantly changed the Earth's surface by transforming natural ecosystems (forests and grasslands) into agroecosystems [65]. The changes in vegetation cover affect the surface heat and water fluxes which, in turn, affect the climate [27, 66]. Bonan [67], in experiments with a modified CCM2 model with prescribed SST, obtained a significant summer cooling effect of land-cover changes on the climate of the United States. Betts [35], using the Hadley Centre climate model HadCM3 with prescribed SST, showed that historical land-cover change results in a reduction in mid-latitude annual mean temperatures within the model.

Experiments with the CLIMBER-2 model revealed that historical land-cover change leads to a cooling of the Earth's surface in comparison with natural land cover [68]. The cooling is notable on the global scale, and is more pronounced in the high and temperate latitudes of the northern hemisphere. In terms of seasonal changes, the maximum cooling in the high northern latitudes occurs in the spring season, emphasising the significance of the albedo effect. The biogeochemical effect of deforestation (warming due to released carbon to the atmosphere) is not directly taken into account.

In comparison with the other studied radiative forcings, deforestation is of the same order of magnitude as $\mathrm{CO}_{2}$ and solar irradiation, although the relative importance of the forcings varies with time (Fig. 5). The model results suggest that until the $19^{\text {th }}$ century, variability in solar irradiance was the major forcing responsible for the climate variability, while a cooling effect of deforestation was growing monotonically. Later, the increasing deforestation rate contributed to a stabilisation of the temperature during the second half of the $19^{\text {th }}$ century, and has damped the $\mathrm{CO}_{2}$ warming in the $20^{\text {th }}$ century. 

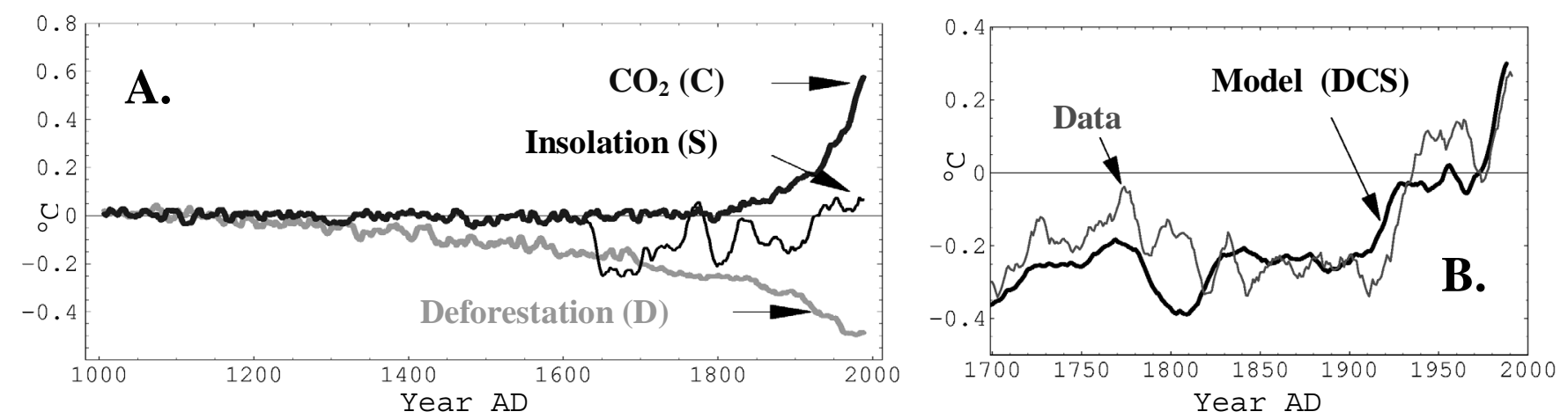

Figure 5. Changes in the mean annual air temperature (in ${ }^{\circ} \mathrm{C}$ ) for the northern hemisphere in CLIMBER-2 simulations [68]. A. Results for reconstructed changes in deforestation (D), $\mathrm{CO}_{2}$ concentration (C), and insolation (S) during the last 1,000 yrs.

B. Results for combined forcings (DCS) against the reconstructed data for the period 1700-1992 [69].

\subsection{Climate-vegetation interaction in Sahara/Sahel region}

Subtropical deserts and semideserts located near the ocean are an interesting illustration of the contraintuitive behaviour of atmospheric processes. For example, the western part of the Sahara is not very far from the Atlantic Ocean. Moisture transport results in significant specific air humidity over the desert, and one might expect that this moisture could lead to rainfall. Moreover, the Sahara is the 'hottest' region in the world as the surface air temperature can rise up to $50^{\circ} \mathrm{C}$ during summer daytimes. The uplift of this hot air with substantial moisture to the altitude of cloud formation $(1-3 \mathrm{~km})$ might contribute to precipitation development. What stops the precipitation formation in the subtropics is the strong influence of a downward branch of Hadley's circulation which results in the reversal of upward vertical velocity to downward velocity at the altitude below the level of cloud development [70]. The descend of dry cold air due to large-scale atmospheric dynamics is the main factor which reduces the precipitation in the subtropics. This factor has a seasonal imprint, as Hadley's circulation cell shifts northwards during the boreal summer and eases pressure on the northern border of the Sahel where most rainfall occurs during the summer.

The dependence of vegetation on climate in subtropical deserts and semideserts can in a first approximation be expressed in terms of precipitation because the vegetation productivity is strictly limited by low water availability. Vegetation does not completely cover the land surface. The drier the climate is, the scarcer is the vegetation and the greater is the fraction of bare soil. The physical characteristics of bare soil (albedo, roughness, and water conductivity) differ from those of vegetation cover. That, in turn, creates a basis for the influence of vegetation on climate.

The Sahara is different from many other subtropical regions. The radiative balance in the region is negative, in other words, there is a net radiative heat loss over the desert. This loss is particularly due to high albedo of the desert, as up to $40 \%$ of incoming radiation is reflected back into space [71]. The radiative mechanism for the Sahara was first explored by Charney [72] who pointed out that the heat loss due to high albedo leads to a horizontal temperature gradient and induces an atmospheric circulation which maintains the sinking motion of dry atmospheric masses and suppresses rainfall over the region. Low precipitation results in little vegetation cover, and the surface albedo is determined by bare ground with a high albedo. This positive feedback supports a desert that is self-sustaining. On the other hand, if there is more precipitation, there is more vegetation; this is darker than sand so the albedo is lower, the surface temperature is higher, and the gradient in temperature between land and ocean increases, amplifying monsoon circulation and upward motion over the desert. As a result, the summer rainfall in the region increases. Another positive vegetation-precipitation feedback active in the region is based on an ability of vascular plants to transpire water from the soil, enhancing evapotranspiration in comparison with bare ground. This hydrological feedback was explored, for example, by Henderson-Sellers et al. [56], Xue and Shukla [72], Eltahir [73]; the main conclusion of these studies being that increased precipitation enhances vegetation cover, evapotranspiration, and, finally, rainfall. 


\subsubsection{The "Green Sahara"}

Both radiative and hydrological feedbacks are positive, i.e. they amplify changes induced by external forcing or internal variability. Could these positive feedbacks affect the system stability? Claussen [74] obtained a positive answer to this question in simulations of a coupled atmospheric GCM, ECHAM-2, and the BIOME model [10]. In these simulations, vegetation cover responded to climate simulated by the GCM and vice versa. The only difference between simulations A and B presented in Fig. 6 was the initial conditions for vegetation cover. In the simulation A (left), which started from the present-day potential vegetation, the desert in the Sahara remained stable. However, when the Sahara was initially covered by forest in the simulation B (right), the system converged to another solution, called the "green" Sahara. The western Sahara is covered by a mixture of shrubs and grass; in addition, vegetation cover in the Sahel region is enhanced. Both desert and green solutions are stable. This is a phenomenon of multiple equilibria due to climate-vegetation interaction in the coupled atmosphere-vegetation model. A similar result of multistability at present-day conditions was obtained by Wang and Eltahir [75] in simulations of a coupled model for the tropical atmosphere and the vegetation model IBIS [18].

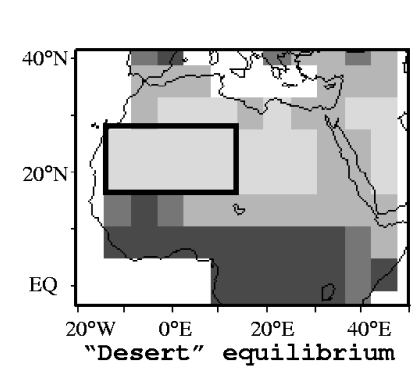

a)

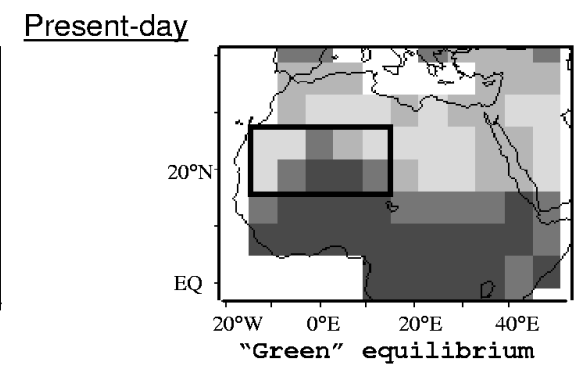

b)

\section{6 kyr BP}

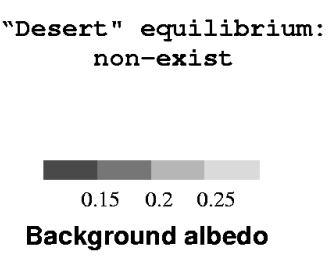

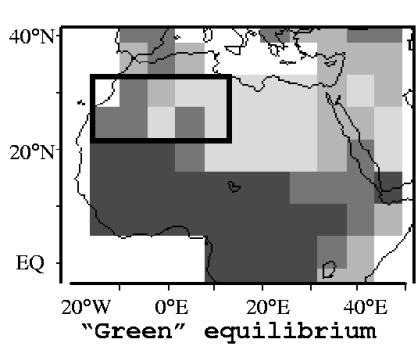

c)

Figure 6. Summary of results obtained with an interactive ECHAM/BIOME model: a, b, present-day climate [74]; c, 6,000 yr BP [76]. A black box indicates study region (West Sahara). Lower albedo corresponds to a higher fraction of vegetation cover. After Brovkin et al. [78].

\subsection{2 "Green Sahara" in the past}

While the Sahara is a desert at present, it was not always desert in the past. Multiple proxy data reveal that during the so-called Holocene optimum, ca. 9,000 - 6,000 years BP (before present), the vegetation cover of the Sahel was greatly extended to the north [78-79]. At that period, the Sahara's climate was much wetter; many lakes and rivers were present in the region including the greatly extended Lake Chad.

A conventional explanation of the "green" Sahara phenomenon in the mid-Holocene in based on the long-term changes in the Earth's orbital parameters [80]. In the early to middle Holocene, the northern hemisphere obtained considerably more solar irradiation during the summer. In the northern subtropical regions, this led to stronger warming over the continent than over the ocean, an increased temperature gradient between land and ocean, and, consequently, intensified monsoon-type circulation in summer which led to increased rainfall over the Sahel/Sahara region. The "orbital forcing" hypothesis as a main mechanism in explaining of mid-Holocene climate changes was tested by Kutzbach and Guetter in 1986 
[81]. Recent intercomparison of GCM simulations with prescribed vegetation cover is discussed by Braconnot et al. [82]. Positive feedbacks between vegetation and precipitation amplified externally induced changes. The role of interactive vegetation was spotlighted by Kutzbach et al. [83], Claussen and Gayler [76], Texier et al. [42], Doherty et al. [84] and in the simulations of the CLIMBER-2 model [40] where the role of the dynamic ocean model was additionally explored.

Results of ECHAM3-BIOME simulations for the mid-Holocene [76] are presented in Fig. 6, c. The system behaves differently to present-day climate. Started from both desert and forest initial conditions, the coupled system converged to the green Sahara solution. That means that desert solution is either absent or unstable: if vegetation is interactive, precipitation increases from iteration to iteration and, finally, the western Sahara is covered by a mixture of grass, shrub, and savannah. But why did the desert solution lose its stability during the mid-Holocene?

\subsubsection{Stability analysis with conceptual and box models of atmosphere-vegetation interaction}

To investigate the system stability, it is useful to reduce the system complexity, i.e. the number of variables describing the system dynamics, to the minimum possible. Similar to the analysis of the foresttemperature feedback in the northern high latitudes described above, we use here two variables, one for vegetation cover and one for the climate, and apply the convenient method of phase plane analysis.

We assumed that under fixed external climate conditions the precipitation $\boldsymbol{P}$ over a sufficiently large and homogeneous area in the subtropics depends only on the averaged vegetation fraction but not on specific types of vegetation cover. This assumption is justified by the fact that the physical characteristics of bare soil (albedo, roughness, and water conductivity) differ substantially from those for any type of vegetation.

By the vegetation fraction $\boldsymbol{V}$ for a large area (comparable with the spatial resolution of general circulation models (GCMs)), we understand a fraction of land covered with any vegetation, at least during some season favourable to vegetation. The other fraction of land is the bare soil, or desert fraction. Generally, $\boldsymbol{V}$ depends on both the temperature and precipitation, but within the narrow temperature interval we can neglect the temperature impact.

The equilibrium manifolds $\boldsymbol{V} *(\boldsymbol{P})$ and $\boldsymbol{P} *(\boldsymbol{V}, \boldsymbol{E})$ are represented by curves on a phase plane (see Fig. 7). The dependence of $\boldsymbol{V} *(\boldsymbol{P})$ in subtropical deserts obeys the following quite general rule: $\boldsymbol{V}$ is near zero up to some threshold $\boldsymbol{P}_{\boldsymbol{c} r}$ then it grows fast, and finally approaches a saturation level $\boldsymbol{V}=1$. The dependency $V^{*}(\boldsymbol{P})$ can be parameterised in different forms: for instance, in a logistic or hyperbolic form. This dependency is a potential one because $\tau$, a characteristic time of vegetation dynamics toward $V^{*}(\boldsymbol{P})$, ranges from years to decades. Precipitation, in turn, increases monotonically while $\boldsymbol{V}$ increases. Generally, $\boldsymbol{P} *(\boldsymbol{V}, \boldsymbol{E})$ is non-linear, but, for simplicity, it is shown as linear in Fig. 7.

Figure 7. Conceptual model of climate-vegetation interaction in the Sahara/Sahel region [77].

The solid curve $\boldsymbol{V}^{*}(\boldsymbol{P})$ represents a dependence of equilibrium vegetation, $\boldsymbol{V}$, on annual mean precipitation, $\boldsymbol{P}$. The dashed line is for equilibrium precipitation response to vegetation cover, $\boldsymbol{P} *(\boldsymbol{V}, \boldsymbol{E})$, under external forcing $\boldsymbol{E}$. System equilibria correspond to the crossing of the curves $\boldsymbol{V}^{*}(\boldsymbol{P})$ and $\boldsymbol{P} *(\boldsymbol{V}, \boldsymbol{E})$. Depending on the position of $\boldsymbol{P}^{*}(\boldsymbol{V}, \boldsymbol{E})$, several cases are possible. Cases I and III correspond to one equilibrium solution, desert $\mathrm{I}^{d}$ and green $\mathrm{II}^{d}$, respectively. Case II corresponds to the stable desert $\mathrm{II}^{d}$ and green $\mathrm{II}^{g}$ equilibria as well as the unstable II* solution. External forcing $\boldsymbol{E}$ (e.g. orbital forcing, atmospheric $\mathrm{CO}_{2}$ concentration) plays the role of a bifurcation parameter by shifting the position of $\boldsymbol{P}^{*}(\boldsymbol{V}, \boldsymbol{E})$.

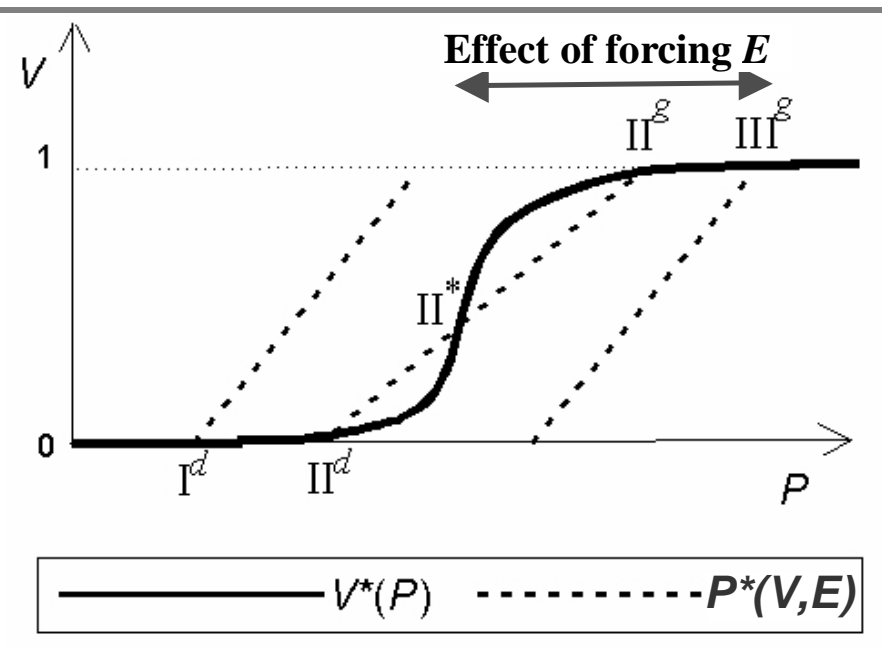


Using the conceptual model, the results of ECHAM-BIOME model have been interpreted [77]. It was shown that present-day climate corresponds to three equilibria (case II in Fig. 7), and the midHolocene corresponds to the unique green equilibrium (case III). The Lyapunov functional reveals one minimum for the mid-Holocene but two for present-day climate (see analogue in Fig. 8,B). Moreover, the minimum corresponding to the green equilibrium for the present day is rather flat. Therefore any sufficiently large perturbation, for instance a prolonged drought such as is observed to occur at the decadal timescale (see, e.g., [85]), could take the system to the desert equilibrium.

The spatial resolution of the CLIMBER-2 model is too coarse to investigate multiple equilibria in the western Saharan region [86]. A box model for climate-vegetation interaction has been developed and applied for Holocene climate [77]. The dynamic climate model accounts for the main processes which influence the summer climate in subtropical deserts: Hadley circulation, zonal wind, monsoon-type circulation, and convection. The vegetation model is similar to the one in the CLIMBER-2 model.

The dynamics of box model solutions in terms of precipitation from the early Holocene to the present day are presented in Fig. 8,A. The two stable branches of the solution, the green branch with relatively high precipitation and the desert branch with low precipitation, are separated by the unstable branch. In the early Holocene, some $10 \mathrm{kyr}$ ago, only the green equilibrium existed in the area with annual precipitation of about $600 \mathrm{~mm} / \mathrm{yr}$. Owing to decreased summer insolation, the precipitation declined to $400 \mathrm{~mm} / \mathrm{yr}$ at the end of mid-Holocene, and the stable desert equilibrium appeared about $6 \mathrm{kyr}$ B.P.

\begin{abstract}
Figure 8. Summary of results of a box model for the western Sahara region for the Holocene [77].

A. Dynamics of system solution in terms of precipitation during the last 10,000 yr. The upper and lower curves are the green and desert solutions, respectively. The dashed line in the middle represents the unstable solution.

B. Multiple steady states, desert and 'green', are shown in a form of Lyapunov potential for vegetation cover. Potential minima, marked by balls, correspond to equilibria that are stable in absence of perturbations. Black and grey balls indicate dominant and minor states, respectively. $8,000 \mathrm{yr}$ BP. The system has only one steady state, green Sahara.

4,000 yr BP. System underwent bifurcation; desert state appeared and became stable. The depths of the well for the two states are approximately equal.

0 yr BP. Both states remain stable but desert has a deeper well. Desert became dominant state as precipitation fluctuations shifted the system towards desert.
\end{abstract}
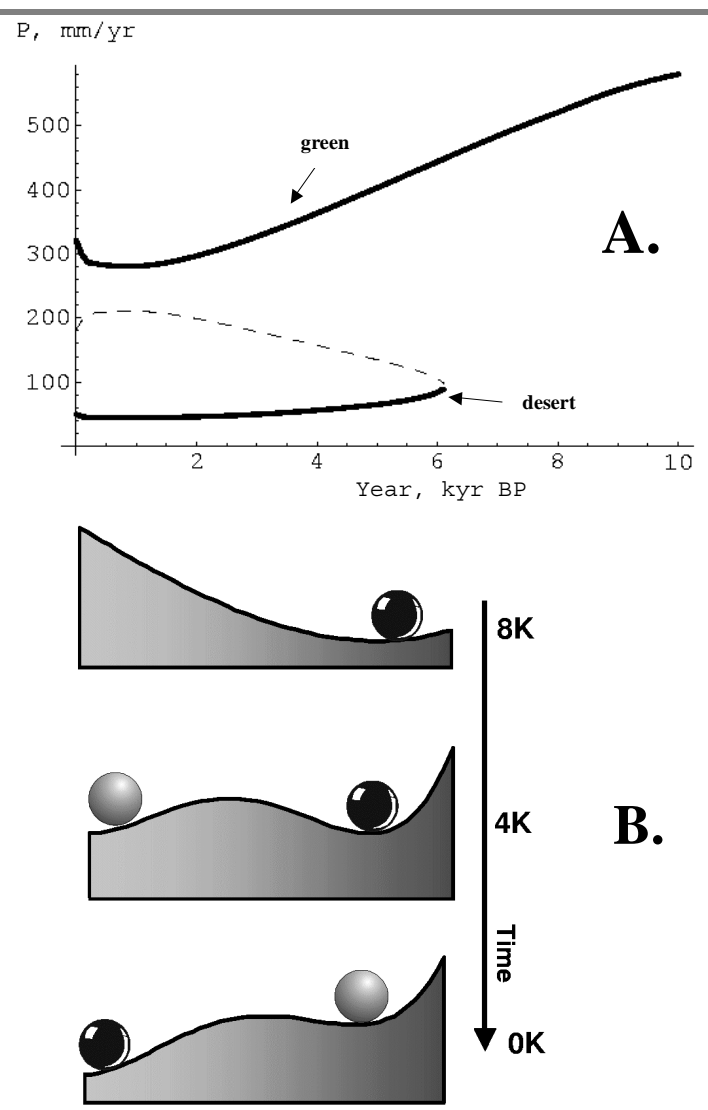

B.

Desert $\longleftarrow$ Vegetation

Fig. 8,B is a simplified cartoon of the system stability under changes in the orbital forcing. The equilibria are shown in a form of the minima of potential function (Lyapunov functional). For 8 kyr BP, there is the single minimum that corresponds to the green equilibrium. For the present day, there are two minima: the desert equilibrium is at an absolute minimum (dominant state) and the green equilibrium is at a relative minimum (minor state). At some $4 \mathrm{kyr}$ BP both equilibria have the same values of the potential. In this sense, the green equilibrium became less stable than the desert equilibrium after $4 \mathrm{kyr}$ BP. More precisely, the switch from one solution to another depends on the possibility for the system to "jump" 
over the maximum which separates the two minima. Accounting for external perturbations helps to explain why the green Sahara lost its stability. The key mechanism might be the significant interannual variability of precipitation in the region which is amplified by interactive vegetation [75, 85]. Any prolonged drought event could push the system towards the desert conditions which are characterised by lower variability in precipitation and, therefore, are self-sustaining at present.

\subsubsection{Global change and the "green Sahara"}

The early and middle Holocene were associated with a warmer climate in the northern temperate and high latitudes, as well as with moister summer climate in the northern subtropics. Simultaneous vegetation expansion and increase in Northern Hemisphere temperatures has provoked the hypothesis that the Sahara would become greener again if anthropogenic greenhouse-gas emissions continue to increase and if, therefore, the global climate becomes warmer and moister again [87]. However, the insolation forcing during the Holocene was season- and hemisphere-dependent, while greenhouse-gas forcing operates in all seasons on a global scale. Therefore, these forcings can have different fingerprints.

For monsoon precipitation in the Sahel/Sahara, the most important forcing is the temperature gradient between land and ocean. Over the land regions with relatively high surface albedo and low humidity, the greenhouse effect is higher than over the adjacent ocean regions [63]. Consequently, the gradient in temperature between the land and ocean could be higher in a greenhouse climate than at present. However, this increase might not be as strong as during the Holocene. Moreover, differences in forcings could results in different changes in zonal atmospheric circulation.

Application of the box model discussed above with certain assumptions about boundary conditions revealed that for a doubled $\mathrm{CO}_{2}$ climate: (i) the model possesses both desert and green equilibria; (ii) the minimum for the green equilibrium is lower than that for the desert equilibrium, i.e. the green state is dominant [77]. Therefore the probability of the realisation of the green equilibrium increases with the increasing $\mathrm{CO}_{2}$ content of the atmosphere within the model.

The hypothesis about a possible future "green Sahara" was investigated in transient simulations with the CLIMBER-2 model [88]. Indeed, some expansion of vegetation cover into the Sahara is possible within the model, if the atmospheric $\mathrm{CO}_{2}$ concentration increases well above pre-industrial values and if vegetation growth is not disturbed. Depending on the rate of changes in atmospheric $\mathrm{CO}_{2}$ concentration the rate of greening can be quite fast (Fig. 9). Sensitivity experiments show that the model results are robust, i.e. the results do not change qualitatively when model parameters are varied. The mid-Holocene "green Sahara" plays the role of a validation test for the parameters. However, the mid-Holocene climate optimum with its strong reduction of North African deserts is not a direct analogue for future greenhousegas induced climate changes. The relative role of mechanisms which lead to a greener Sahara is different in greenhouse climate, and the amplitude of simulated vegetation-cover changes in North Africa is less than estimated for mid-Holocene climate.

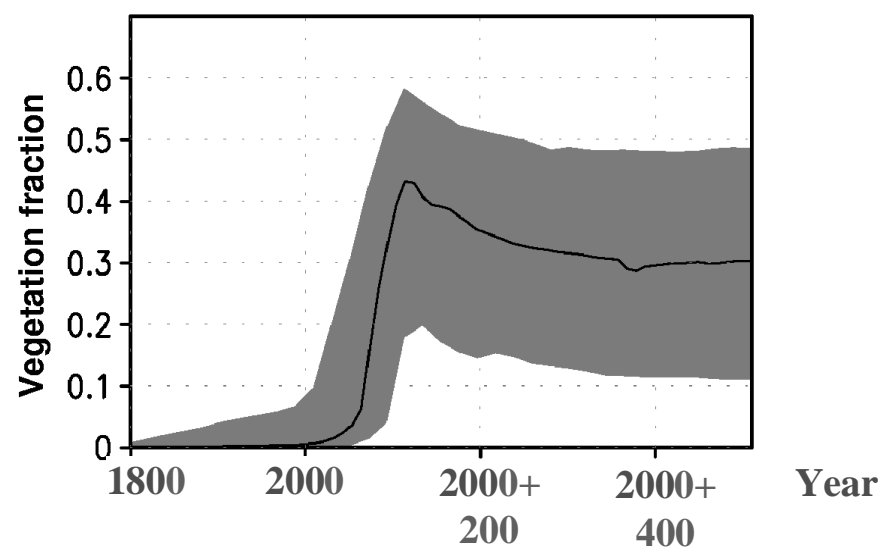

Figure 9. Changes in vegetation fraction in Sahara region under extreme scenario of $\mathrm{CO}_{2}$ emissions (stabilisation level of 1000 ppmv around year 2000+100). The shaded area represents uncertainty in the model parameters. After Claussen et al. [88]. 


\section{Acknowledgements}

The author thanks Vladimir Petoukhov, Martin Claussen, Andrey Ganopolski, Claudia Kubatzki and other colleagues in the CLIMBER group who have stimulated his interest in climate research over the years. Discussions with Yuri Svirezhev, Wolfgang Cramer, Sam Lewis and Michel Crucifix were very fruitful. The author is grateful to Alison Schlums for editing the manuscript.

\section{References}

[1] Woodward F.I., Climate and plant distribution (Cambridge University Press, 1987) 174 pp.

[2] Whittaker R.H., Communities and Ecosystems (MacMillan, New York, 1975) 385 pp.

[3] Von Humbolt, A., Essai sur la Geographie des Plantes (Levrault, Schoell et Compagnie, Paris, 1807) $155 \mathrm{pp}$.

[4] Cox C.B., Moore P.D., Biogeography: An Ecological and Evolutionary Approach (Blackwell, London, 2000) 298 pp.

[5] Grime P.J., Plant Strategies, Vegetation Processes, and Ecosystem Properties (John Wiley \& Sons, 2001) $456 \mathrm{pp}$.

[6] Brown J.H., Macroecology (University of Chicago Press, 1995) 269 pp.

[7] Blackburn T.M., Gaston K.J., Global Ecology \& Biogeography, 11 (2002) 185-189.

[8] Köppen W., Das geographische System der Klimate. In: Handbuch der Klimatologie, ed. by Köppen W., Geiger R. (Borntraeger, Berlin, 1936) 46 pp.

[9] Holdridge L.R., Science 105 (1947) 367-368.

[10] Prentice I.C., Cramer W., Harrison S.P., Leemans R., Monserud R.A., Solomon A.M., Journal of Biogeography 19 (1992) 35-57.

[11] DeFries R.S., Hansen M.C., Townshend J.R.G., Janetos A.C, Loveland T.R., Global Change Biology 6 (2000) 247-254.

[12] Melillo, J.M., McGuire, A.D., Kicklighter, D.W., Moore, B. III, Vörösmarty, C.J., Schloss, A.L., Nature 363 (1993) 234-240.

[13] Lüdeke M., Badeck F.-W., Otto R., Häger C., Dönges S., Kindermann J., Würth G., Lang T., Jäkel U., Klaudius A., Ramge P., Habermehl S., Kohlmaier G., Climate Research 4 (1994) 143-166.

[14] Haxeltine, A., Prentice, I.C., Global Biogeochemical Cycles, 10 (1996) 693-709.

[15] Kittel T.G.F., Rosenbloom N.A., Painter T.H., Schimel D.S., Melillo J.M., Pan Y.D., Kicklighter D.W., McGuire A.D., Neilson R.P., Chaney J., Ojima D.S., McKeown R., Parton W.J., Pulliam W.M., Prentice I.C., Haxeltine A., Running S.W., Pierce L.L., Hunt E.R., Smith T.M., Rizzo B., Woodward F.I., Journal of Biogeography 22 (1995) 857-862.

[16] Cramer W., Kicklighter D.W., Bondeau A., Moore B., Churkina C., Nemry B., Ruimy A., Schloss A.L., Kaduk J., and the participants of the Potsdam NPP Model Intercomparison, Global Change Biology 5 (1999) 1-15.

[17] Arora, V., Reviews of Geophysics 40 (2002) 1006, DOI: 10.1029/2001RG000103.

[18] Foley J.A., Prentice C. I., Ramankutty N., Levis S., Pollard D., Sitch S., Haxeltine A., Global Biogeochemical Cycles 10 (1996) 603-628.

[19] Cramer W., A. Bondeau, F.I. Woodward, I.C. Prentice, R.A. Betts, V. Brovkin, P.M. Cox, V. Fisher, J. Foley, A.D. Friend, C. Kucharik, M.R., Lomas, C. Molling, N. Ramankutty, S. Sitch, B. Smith, A. White, C. Young-Molling, Global Change Biology 7 (2001) 357-373.

[20] Cox P.M., Description of the TRIFFID dynamic global vegetation model, Tech. Note 24 (Hadley Cent., Bracknell, UK, 2001) 16 pp.

[21] Svirezhev Y.M., Ecological Modelling 124 (1999) 131-144.

[22] Dickinson R.E., Henderson-Sellers A., Kennedy P.J., Wilson M.F., Biosphere-atmosphere transfer scheme (BATS) for the NCAR community climate model, NCAR Technical Note TN-275+STR (Boulder, Colorado, 1986) 69 pp. 
[23] Sellers P.J., Dickinson R.E., Randall D.A., Betts A.K., Hall F.G., Berry J.A, Collatz G.J, Denning A.S., Mooney H.A., Nobre C.A., Sato N., Field C.B., Henderson-Sellers A., Science 275 (1997) 502509.

[24] Rosen R.D., The global energy cycle. In: Global Energy and Water Cycles, ed. by Browing K.A., Gurney R.J. (Cambridge University Press, 1999) pp. 1-9.

[25] Betts A.K., Ball J.H., Journal of Geophysical Research 102 (1997) 28,901-28,909.

[26] Pielke R.A, Vidale P.L., Journal of Geophysical Research 100 (1995) 25,755-25,758.

[27] Pielke R.A., Avissar R., Raupach M., Dolman A.J., Zeng X., Denning A.S., Global Change Biology 4 (1998) 461-475.

[28] Brovkin, V., Levis S., Loutre M.-F., Crucifix M., Claussen M., Ganopolski A., Kubatzki C., Petoukhov V., Climatic Change, in press.

[29] Otterman J., Chou M.D., Arking A., J.Clim. Appl. Meteorol. 23 (1984) 762-767.

[30] Harvey L.D.D., Climatic Change 13 (1988) 191-224.

[31] Bonan G.B., Pollard D., Thompson S.L., Nature 359 (1992) 716-718.

[32] Thomas G., Rowntree P.R., Q. J. R. Meteorol. Soc. 118 (1992) 469-497.

[33] Chalita, S., Le Treut H., Climate Dynamics 10 231-240.

[34] Bonan G.B., Chapin F.S., Thompson S.L., Climatic Change 29 (1995) 145-167.

[35] Betts R.A., in H. Ritchie (ed) Research Activities in Atmospheric and Oceanic Modelling, CAS/JSC WGNE Report No. 28, WMO, (1999) p. 7.11-7.12.

[36] Kleidon A., Fraedrich K., Heimann M., Climatic Change 44 (2000) 471-493.

[37] Heck P., Luthi D., Wernli H., Schar C., Journal of Geophysical Research 106, (2001) 7,817-7,835.

[38] Foley J., Kutzbach J.E., Coe M.T., Levis S., Nature 371 (1994) 52-54.

[39] Claussen M., Gayler V., Global Ecology and Biogeography Letters 6, (1997) 369-377.

[40] Ganopolski A., Kubatzki C., Claussen M., Brovkin V., Petoukhov V., Science 280 (1998) 1,916$1,919$.

[41] Hewitt C.D., Mitchell J.F.B., Geophysical Research Letters 25 (1998) 361-364.

[42] Texier D., de Noblet N., Harrison S.P., Haxeltine A., Jolly D., Joussaume S., Laarif F., Prentice I.C., Tarasov P., Climate Dynamics 13 (1997) 865-882.

[43] Crucifix M., Loutre M.F., Tulkens P., Fichefet T., Berger A., Climate Dynamics 19 (2002) 43-60.

[44] Kubatzki C., Claussen M., Climate Dynamics 14 (1998) 461-471.

[45] Levis S., Foley J.A., Pollard D., Journal of Geophysical Research 104 (1999) 31,191-31,198.

[46] Gallimore R.G., Kutzbach J.E., Nature 381 (1996) 503-505.

[47] de Noblet N.I., Prentice I.C., Joussaume S., Texier D., Botta A., Haxeltine A., Geophysical Research Letters 23 (1996) 3191-3194.

[48] Kubatzki C., Montoya M., Rahmstorf S., Ganopolski A., Claussen M., Climate Dynamics 16 (2000) 799-814.

[49] Crucifix M., Loutre M.F. Climate Dynamics 19 (2002): 417-433.

[50] Rahmstorf S., Marotzke J., Willebrand J., Stability of the thermohaline circulation. In: The warm water sphere of the North Atlantic Ocean, ed. by W. Krauss (Borntraeger, Stuttgart, 1996) pp. 129158.

[51] Levis S., Foley J.A., Brovkin V., Pollard D., Global Ecology and Biogeography 8 (1999) 489-500.

[52] Petoukhov V., Ganopolski A., Brovkin V., Claussen M., Eliseev A., Kubatzki C., Rahmstorf S., Climate Dynamics 16 (2000) 1-17.

[53] Ganopolski A., Petoukhov V., Rahmstorf S., Brovkin V., Claussen M., Eliseev A, Kubatzki C., Climate Dynamics 17 (2001) 735-751.

[54] Serreze M.C., Walsh J.E., Chapin F.S., Osterkamp T., Dyurgerov M., Romanovsky V., Oechel W.C., Morison J., Zhang T., Barry R.G., Climatic Change 46 (2000) 159-207.

[55] Lucht W., Prentice I.C., Myneni R.B., Sitch S., Friedlingstein P., Cramer W., Bousquet P., Buermann W., Smith B., Science 296 (2002) 1687-1689.

[56] Henderson-Sellers A., Dickinson R.E., Durbidge T.B., Kennedy P.J., McGuffie K., Pitman A.J., Journal of Geophysical Research 98 (1993) 7289-7315.

[57] Polcher, J., Laval, K., Climate Dynamics 10 (1994) 205-219. 
[58] Zhang, H., McGuffie K., Henderson-Sellers A., Journal of Climate 9 (1996) 1,497-1,517.

[59] Chase T.N., Pielke R.A., Kittel T.G.F., Nemani R.R., Running S.W., Climate Dynamics 16 (2000) 93-105.

[60] Dolman A.J., Silva Dias M.A., Calvet J.C., Ashby M., Tahara A.S., Delire C., Kabat P., Fisch G.A., Nobre C.A., Annales Geophysicae-Atmospheres Hydrospheres And Space Sciences 17 (1999) 1,0951,110 .

[61] Avissar, R., Journal of Geophysical Research 97 (1998) 2729-2742.

[62] Cox P.M., Betts R.A., Jones C.D., Spall S.A., Totterdell I.J., Nature 408 (2000) 184-187.

[63] Climate Change 2001: The Scientific Basis, ed. by Houghton J.T., Ding Y., Griggs D.J., Noguer M., van der Linden P., Dai X., Maskell K., Johnson, C.I. (Cambridge University Press, 2002).

[64] Friedlingstein P., Bopp L., Ciais P., Dufresne J.L., Fairhead L., LeTreut H., Monfray P., Orr J., Geophysical Research Letters 28 (2001) 1543-1546.

[65] Ramankutty N., Foley J.A., Global Biogeochemical Cycles 13 (1999) 997-1027.

[66] Dickinson, R.E., Changes in land-use. In: Climate System Modelling, ed. by K.E. Trenberth (Cambridge Univ. Press, 1992) pp. 689-700.

[67] Bonan G.B., Climatic Change 37 (1997) 449-486.

[68] Brovkin V., Ganopolski A., Claussen M., Kubatzki C., Petoukhov V., Global Ecology and Biogeography 8 (1999) 509-517.

[69] Mann M.E., Bradley R.S., Hughes M.K., Nature 392 (1998) 779-787.

[70] Webster P.J., Magana V.O., Palmer T.N., Shukla J., Tomas R.A., Yanai M., Yasunari T., Journal of Geophysical Research 103 (1998) 14451-14510.

[71] Knorr W., Schnitzler K.G., Govaerts Y., Geophysical Research Letters 28 (2001) 3489-3492.

[72] Xue Y., Shukla J., Journal of Climate 6 (1993), 2232-2245.

[73] Eltahir E.A.B., Journal of Geophysical Research 101 (1996): 4255-4268.

[74] Claussen M., Climate Research 4 (1994) 203-221.

[75] Wang G.L., Eltahir E.A.B., Quarterly Journal of the Royal Meteorological Society, part B 126 (2000): 1261-1280.

[76] Claussen M, Gayler V., Global Ecology and Biogeography Letters 6 (1997) 369-377.

[77] Brovkin V., Claussen M., Petoukhov V., Ganopolski A., Journal of Geophysical Research 103 (1998) 31,613-31,624.

[78] Hoelzmann P., Jolly D., Harrison S.P., Laarif F., Bonnefille R., Pachur H.-J., Global Biogeochemical Cycles 12 (1998) 35-52.

[79] Prentice I.C., Jolly D., and BIOME 6000 participants, Journal of Biogeography 27 (2000) 507-519.

[80] Berger A., Orbital variations. In: Encyclopaedia of Climate and Weather, ed. by S. Schneider (Oxford Univ. Press, New York, 1996) pp. 557-564.

[81] Kutzbach J.E., Guetter P.J., Journal of the Atmospheric Sciences 43 (1986) 1726-1759.

[82] Braconnot P., Loutre M.F., Dong B., Joussaume S., Valdes P., and PMIP participating groups, Climate Dynamics 19 (2002) 107-121.

[83] Kutzbach J.E., Bonan G., Foley J., Harrison S.P., Nature 384 (1996) 623-626.

[84] Doherty R., Kutzbach J., Foley J., Pollard D., Climate Dynamics 16 (2000) 561-573.

[85] Zeng N., Neelin J.D., Lau K.M., Tucker C.J., Science 286 (1999) 1537-1540.

[86] Claussen M., Kubatzki C., Brovkin V., Ganopolski A., Hoelzmann P., Pachur H.-J., Geophysical Research Letters 26 (1999) 2037-2040.

[87] Petit-Maire N., Episodes 13 (1990) 103-107.

[88] Claussen M., Brovkin V., Ganopolski A., Kubatzki C., Petoukhov V., Climatic Change, in press. 